\title{
BMJ Open Health-seeking behaviour and cost of fever treatment to households in a malaria-endemic setting of northern Ghana: a cross-sectional study
}

\author{
Maxwell Ayindenaba Dalaba (D) , ${ }^{1}$ Paul Welaga, ${ }^{2,3}$ Philip Ayizem Dalinjong (D) , ${ }^{3}$ \\ Samuel Chatio, ${ }^{3}$ Mustapha Immurana, ${ }^{1}$ Robert Kaba Alhassan, ${ }^{1}$ Desmond Klu, ${ }^{1}$ \\ Alfred Kwesi Manyeh (D) , ${ }^{1}$ Isaiah Agorinya, ${ }^{4}$ Abraham Oduro, ${ }^{3}$ \\ Philip Baba Adongo, ${ }^{5}$ Patricia Akweongo ${ }^{5}$
}

To cite: Dalaba MA, Welaga $P$, Dalinjong PA, et al. Healthseeking behaviour and cost of fever treatment to households in a malaria-endemic setting of northern Ghana: a crosssectional study. BMJ Open 2021;11:e052224. doi:10.1136/ bmjopen-2021-052224

- Prepublication history and additional supplemental material for this paper are available online. To view these files, please visit the journal online (http://dx.doi.org/10.1136/ bmjopen-2021-052224).

Received 10 April 2021 Accepted 19 August 2021

Check for updates

(C) Author(s) (or their employer(s)) 2021. Re-use permitted under CC BY-NC. No commercial re-use. See rights and permissions. Published by BMJ.

For numbered affiliations see end of article.

Correspondence to Dr Maxwell Ayindenaba Dalaba; madalaba@yahoo.com

\section{ABSTRACT}

Objectives To examine the health-seeking behaviour and cost of fever treatment to households in Ghana.

Design Cross-sectional household survey conducted between July and September 2015.

Setting Kassena-Nankana East and West districts in Upper East region of Ghana.

Participants Individuals with an episode of fever in the 2 weeks preceding a visit during routine health and demographic surveillance system data collection were selected for the study. Sociodemographic characteristics, treatment-seeking behaviours and cost of treatment of fever were obtained from the respondents.

Results Out of 1845 households visited, 21\% (393 of 1845) reported an episode of fever. About 50\% (195 of 393) of the fever cases had blood sample taken for testing by microscopy or Rapid Diagnostic Test, and 73.3\% (143 of 195) were confirmed to have malaria. Of the 393 people with fever, $70 \%$ (271 of 393) reported taking an antimalarial and $24.0 \%$ (65 of 271) took antimalarial within 24 hours of the onset of illness. About 54\% (145 of 271) of the antimalarials were obtained from health facilities.

The average cost (direct and indirect) incurred by households per fever treatment was GH\$27.8/US\$7.3 (range: GHc0.2/US\$0.1-GH\$200/US\$52.6). This cost is 4.6 times the daily minimum wage of unskilled paid jobs of Ghanaians (US\$1.6). The average cost incurred by those enrolled into the National Health Insurance Scheme (NHIS) was GH\$24.8/US\$6.5, and GH৫50/US\$11.6 for those not enrolled.

Conclusions Prompt treatment within 24 hours of onset of fever was low (24\%) compared with the Roll Back Malaria Programme target of at least $80 \%$. Cost of treatment was relatively high when compared with average earnings of households in Ghana and enrolment into the NHIS reduced the cost of fever treatment remarkably. It is important to improve access to malaria diagnosis, antimalarials and enrolment into the NHIS in order to improve the case management of fever/malaria and accelerate universal health coverage in Ghana.
Strengths and limitations of this study

- Study offers insights on health seeking and costs of fever treatment in a malaria-endemic area.

- Study includes indirect costs, a cost element that is often ignored in cost of illness studies.

- The framework used for selection of respondents allowed representativeness of the study.

- Possibility of recall bias because of the 2-week recall period.

- The use of self-reported fever as a proxy for malaria is a potential limitation.

\section{BACKGROUND}

According to the WHO, an estimated 228 million malaria cases and 405000 malaria deaths were recorded worldwide in 2018. The burden of malaria is more severe in the WHO African region as it accounted for $94 \%$ of all malaria deaths in 2018. ${ }^{1}$ It is a major cause of poverty and slows economic growth by up to $1.3 \%$ per year in endemic countries. ${ }^{2}$

Malaria is a major public health problem in Ghana where it accounts for $30 \%$ of all outpatient attendances and $23 \%$ of inpatient admissions. ${ }^{3}$ The disease poses significant economic burden to households in Ghana and may lead to catastrophic payments, particularly in poor households. ${ }^{4}$ For instance, a study conducted in the middle belt of Ghana reported that households incurred a mean cost of GH $\not 22.2$ (\$14.6) for fever treatment. ${ }^{2}$ Another study in the Upper West region of northern Ghana revealed that households paid an average of US\$4.91 in treating an under-5 malaria case. ${ }^{4}$

Malaria is a preventable and treatable illness. The main methods for the prevention of malaria include the use of long-lasting insecticidal nets, indoor residual spraying, use of intermittent preventive treatment for 
pregnant women and vector control methods such as larviciding. ${ }^{56}$ The WHO has recommended that all persons from endemic areas with suspected malaria should be examined for evidence of infections with malaria parasites by Rapid Diagnostic Test (RDT) or microscopy. In addition, the WHO recommended that uncomplicated malaria should be treated with antimalarials such as artemisinin-based combination therapies (ACTs), particularly in areas where malaria is endemic, and patients should have access to ACTs within 24 hours of onset of malaria. ${ }^{6}$ The recommended ACT combinations are artemether-lumefantrine (AL), artesunate-amodiaquine (AA), artesunate-mefloquine, dihydroartemisinin-piperaquine (DP), and artesunate-sulfadoxine-pyrimethamine. The choice of ACT in a country or region is based on the level of resistance of the partner medicine in the combination. ${ }^{7}$

Following the WHO recommendation, Ghana changed its antimalarial drug policy, choosing AA combination as the first-line drug for the treatment of uncomplicated malaria to replace chloroquine in 2004. However, the implementation process had challenges which were related to adverse drug reactions, safety concerns and absence of other treatment options. It therefore became necessary to review the new policy to address all recognised concerns. A task force reviewed the existing policy and selected additional ACT drugs and dosage forms to cater for those who could not bear the AA combination. Two additional first-line ACTs, namely: AL and DP were selected, thus making Ghana to have three official first-line antimalarial drugs. ${ }^{8}$

However, fever/malaria diagnosis, prompt treatment, access to ACTs as well as costs of fever treatment have not been extensively studied in Ghana, particularly in malaria-endemic and perennial areas such as the Kassena-Nankana districts of Ghana. ${ }^{9}$ These districts are located in the Upper East region where the prevalence of fever is high. The Ghana living standard survey round 6 reported fever prevalence of $13 \%$ in children under age 5 in the region. ${ }^{10}$ In addition, poverty is widespread in the region, and this can affect health seeking and cost of fever treatment. ${ }^{11}$ In the context of increasing attention towards improving malaria control, coupled with budget constraints and competing healthcare problems, it is important to provide policymakers with researched information on the economic burden of fever to guide them in future malaria control interventions. This study therefore examined the health-seeking behaviours and cost of fever treatment to households in the Kassena-Nankana East and West districts of Ghana.

\section{METHODS}

\section{Study area}

The study was carried out in the Kassena-Nankana East and West districts of the Upper East region of Ghana. The Kassena-Nankana East is home to the Navrongo Health Research Centre which operates a Health and
Demographic Surveillance System (HDSS), and has a database of all individuals and households in the KassenaNankana East and West districts.

For the purpose of this study, we refer to the two districts by the former name-the Kassena-Nankana District (KND). The KND covers an area of about 1674 $\mathrm{km}^{212}$ and the area is characterised by a short rainy season and a prolonged dry season from October to March. The mean annual rainfall is about $850 \mathrm{~mm}$, with the heaviest usually occurring in August. The total population currently under surveillance is about 152000 , residing in about 32000 households. ${ }^{12}{ }^{13}$ Malaria transmission in the KND occurs all year round but there is a distinct seasonal pattern with the peak of transmission coinciding with the period of the major rains (August) and the dry season experiencing very low rates of malaria infection. ${ }^{10}$

The study area has one district referral hospital located in Navrongo town and eight health centres strategically located across the districts to provide healthcare. There are 28 Community-Based Health Planning and Services (CHPS) compounds/clinics located in various communities providing primary healthcare treatment for minor ailments, including malaria treatment as well as carrying out childhood immunisations and antenatal services. There are 3 private clinics, 3 pharmacies and 50 licensed chemical shops in the area.

\section{Study design}

This was a cross-sectional study and part of a larger phase IV research study funded through the International Network for the Demographic Evaluation of Populations and their Health (INDEPTH). The INDEPTH Network is an umbrella organisation for a group of independent health research centres operating HDSS sites in low/ middle-income countries. ${ }^{14}$ The overall aim of the phase IV research study was to assess the safety and effectiveness of new malaria treatments as well as their determinants in real-life health systems. ${ }^{215}$

\section{Sample size and data collection}

From the 2014 Ghana Demographic and Health Survey report, fever prevalence in the country was $13.8 \% .^{10}$ Due to the seasonal variation of malaria prevalence, we assumed, conservatively, that $6 \%$ of the population (ie, about half of the national prevalence) would have had fever 2 weeks prior to the interview date and that about $50 \%$ of the population with fever will seek care and have access to an official point of ACT provision within 24 hours. We accounted for clustering within households by using a design effect of 1.5 . We further allowed a $10 \%$ dropout rate to achieve a sample size of 1845 households with approximately 9225 household members.

The data for this study were collected as an additional module within the framework of the Navrongo HDSS round updates. Under the HDSS, field workers visit all households every 4-6 months to collect and update health and sociodemographic information (including, births, deaths, pregnancies, marriages, migrations, household assets) of 
households. ${ }^{12} 13$ Data collectors visited the sampled households between July and September 2015. Only one person in a selected household with a history of fever in the 2 weeks preceding the survey who sought care was interviewed. Interviews were conducted with adult respondents who were 18 years or above after obtaining informed consent. Children aged 12-17 years were interviewed after they provided informed assent. However, for children who were less than 12 years of age, their adult caretakers were interviewed. Information on sociodemographic characteristics, treatment-seeking behaviours and cost of treatment was obtained from respondents who sought treatment due to fever. Information on costs of treatment was obtained from the patient perspective.

The sociodemographic characteristics included age, sex, health insurance status and main occupation. Questions on fever and treatment included whether antimalarials were taken and the type of antimalarials taken, how many days after the onset of fever patient sought treatment, where the patient sought treatment and whether blood sample was taken to test for malaria.

We also collected data on direct medical costs and direct non-medical costs for seeking care for the illness. Direct medical cost included cost of consultation, medicines, self-medication (medicines bought from drug stores without prescription), laboratory tests and hospitalisation. Direct non-medical costs comprised of cost of transportation, lodging, meals and telephone expenses. Respondents also answered questions on productivity days lost due to illness. The questionnaire is included in the online supplemental file 1 .

Patients treated with antimalarial drugs were asked for the name of the drug, and a data collector physically observed the drugs if it was still in use or if the package was available. Data collectors carried photo images of the different varieties of antimalarial packages (brand and generic names) available from private and public providers in the district to facilitate identification of the antimalarial drugs used for treatments. The types of antimalarial drugs were captured on a sheet by their generic names. For instance, brands such as Camosunate, Amonate and Coarsucam were captured as AA; Malar-2, Lonart, Lumartem, Coartem, Co-Malagon and Lumether as AL; P-Alaxin, Eurartesin and Duo-Cotecxin as DP; and other antimalarial drugs which were not in our drugs list were classified as other antimalarials.

\section{Patient and public involvement}

We did not involve patients and the public in the designing stage of the study.

\section{Data management and analysis}

Data were double entered on FoxPro and transferred into Stata V.16.0 for analysis. We used descriptive statistics showing proportions, frequencies and means. The total cost of fever treatment per episode was calculated by summing the direct and indirect costs incurred by households. The direct cost included both direct medical cost and non-medical costs. The direct medical costs covered
Table 1 Background characteristics of respondents

\begin{tabular}{llll}
\hline Characteristics & Categories & $\begin{array}{l}\text { Frequency } \\
\text { (n=393) }\end{array}$ & Per cent \\
\hline Age (years) & Under 5 & 102 & 26.0 \\
& $5-14$ & 65 & 16.5 \\
& $15-49$ & 49 & 12.5 \\
& Above 49 & 177 & 45.0 \\
Sex & Male & 190 & 48.4 \\
& Female & 203 & 51.7 \\
Insurance status & Insured & 327 & 83.2 \\
& Uninsured & 66 & 16.8 \\
Actively engaged in & Yes & 127 & 32.3 \\
income-generating & No & 266 & 67.7 \\
activity & & 51 & 40.2 \\
Occupation of those & Farmer & & 22.1 \\
actively engaged in & Public & 28 & 37.8 \\
income-generating & service $\dagger$ & & \\
activity & Artisan $\ddagger$ & 48 & \\
\hline
\end{tabular}

${ }^{*}$ Cultivating of crops and rearing of animals.

†Teacher, doctor, nurse and any government worker.

$\ddagger$ Hair dresser, dressmaker, plumber, mason, craftsperson and carpenter.

all out-of-pocket (OOP) payments for consultation, diagnosis (laboratory), and medicines bought at heath facilities and drug shops. The direct non-medical costs included all OOP payments for transportation to and from health facilities (patient and caregiver) and other costs such as lodging, meals and telephone expenses.

Indirect cost (productivity lost) followed the human capital approach, consisting of the opportunity cost of the time loss for productive activities due to illness or caregiving. ${ }^{216}$ Indirect cost was estimated by multiplying the number of days lost due to fever by the average daily minimum wage for the year 2015 (GH\&7/US\$1.8) for Ghanaians in unskilled paid jobs. ${ }^{17}$ In an area characterised by low literacy and high informal workers, the use of human capital approach was appropriate. $^{218}$ The productivity lost was calculated for both the patient and the caretaker who were actively engaged in an income-generating activity prior to the illness. In-patient or admission was defined as those who were detained in a health facility for fever for longer than 12 hours. ${ }^{4}$ In-patient costs were therefore the sum of medical costs, laboratory costs and bed costs during the admission. All costs were in Ghana cedis $(\mathrm{GH} \phi)$ and results presented in both GH $\angle$ and US\$. The conversion rate of GH $\angle$ to US $\$$ was based on the average exchange rate for 2015 at US $\$ 1=\mathrm{GH} \not 3.8 .^{19}$

\section{RESULTS}

\section{Background characteristics}

Table 1 shows the background characteristics of respondents. Out of the 1845 households visited, 21.3\% (393 of 1845) had at least one person with an episode of fever in the 2 weeks preceding the survey. Only one person 
with an episode of fever in the 2 weeks preceding the survey was interviewed in a household. The average age of patients with fever was 25 years, $45 \%$ ( 177 of 393) were above 49 years old and 26\% (102 of 393) were under 5 years of age. There were slightly more female fever cases, $51.7 \%$ (203 of 393) than male cases, $48.4 \%$ (190 of 393). About $83.2 \%$ (327 of 393) of patients had valid National Health Insurance Scheme (NHIS) cards at the time of illness, and $32.3 \%$ (127 of 393) were actively engaged in income-generating activities. Out of those who were actively engaged in income-generating activities, $40.2 \%$ (51 of 127) were farmers, $37.8 \%$ (48 of 127) were artisans and $22.1 \%$ (28 of 127) were public servants.

\section{Fever diagnoses and treatment-seeking behaviours}

Out of the 393 patients with fever interviewed, $49.6 \%$ (195 of 393) had their blood sample taken for testing by microscopy or RDT and 47.1\% (185 of 393) were confirmed to have malaria. Among the 195 who had their blood sample taken, $73.3 \%$ (143 of 195) were confirmed to have malaria. Of the 393 patients with fever, $70 \%$ (271 of 393) reported taking an antimalarial (ACT) and $72.8 \%$ (286 of 393) took antipyretics. Out of the 143 confirmed malaria cases, $96.5 \%$ (138 of 143) took an antimalarial, and out of the 198 who did not test for malaria, $57.6 \%$ (114 of 198) also took antimalarial drugs (table 2).

With regard to prompt treatment, 24\% (65 of 271) took an antimalarial within 24 hours, 43.2\% (117 of 271) took an antimalarial between 25 and 48 hours, and $33.8 \%$ (89 of 271) took an antimalarial after 48 hours of onset of fever (table 3). A similar trend of low prompt treatment within 24 hours was observed when treatment was

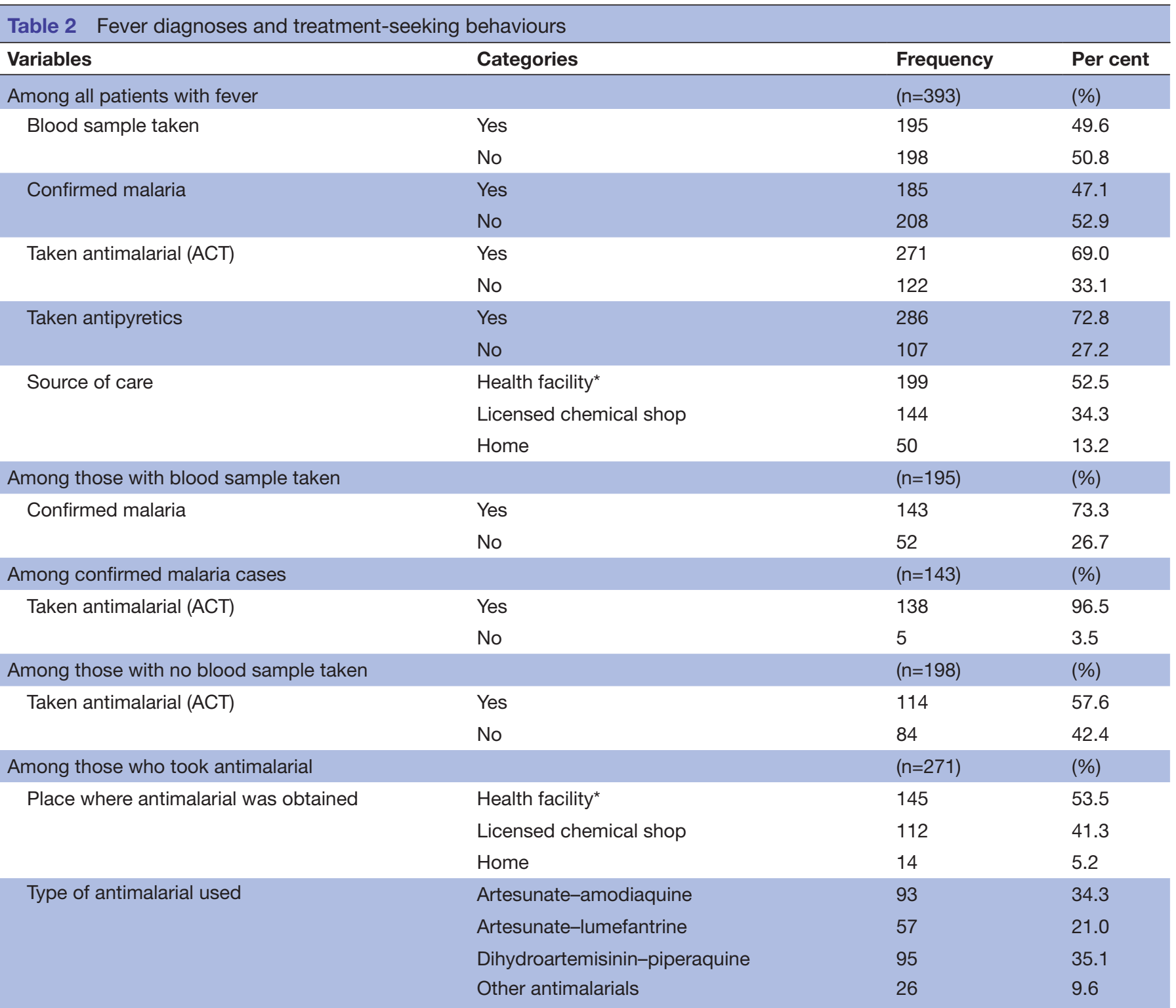

*Hospitals, health centres, clinics and CHPS.

ACT, artemisinin-based combination therapy; CHPS, Community-Based Health Planning and Services. 
Table 3 Time spent between onset of fever and start of antimalarial treatment

\begin{tabular}{lccc}
\hline & With blood test & Without blood test & Combined \\
\hline Time spent before start of antimalarial & Frequency (\%) & Frequency (\%) & Frequency (\%) \\
Within 24 hours & $34(21.7)$ & $31(27.2)$ & $65(24.0)$ \\
Between 25 and 48 hours & $62(39.5)$ & $55(48.3)$ & $117(43.17)$ \\
More than 48 hours & $61(38.9)$ & $28(24.6)$ & $89(32.8)$ \\
Total & $157(100)$ & $114(100)$ & $271(100)$ \\
\hline
\end{tabular}

disaggregated into respondents with blood test done and those without blood test done.

Regarding the type of antimalarial patients used, $35.1 \%$ (95 of 271) indicated they took DP, 34.5\% (93 of 271) took AA and 21.0\% (57 of 271) took AL. Among those who took antimalarials, $53.5 \%$ (145 of 271) obtained them from formal health facilities (hospitals, health centres, clinics and CHPS), 41.3\% (112 of 271) from pharmacy or chemical shops, and 5.2\% (14 of 271) from home (leftover medicine) (table 2).

\section{Cost of treating fever}

Table 4 presents direct and indirect costs of treating fever. Out of the 393 patients with fever, 97.2\% (382 of 393) incurred cost (OOP). Among those who incurred treatment cost for fever, the overall average cost (direct and

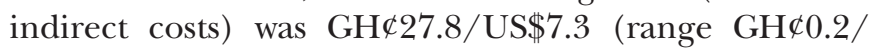
US\$0.1-GH $\not 200 /$ US\$52.6). The average cost of treatment was a little lower at GH $\not 27 / \mathrm{US} \$ 7.1$ when all 393 fever cases (both those who incurred cost and those who did not) were used to calculate the average cost.

By disaggregating costs into antimalarial and antipyretics, the overall average cost incurred by patients who took antimalarials (271) was GH $427.5 / \mathrm{US} \$ 7.2$ and for antipyretics (286) was GH\&27.1/US\$7.1.

Of those who incurred costs of treatment, 36.6\% (140 of 382) incurred direct medical costs during fever treatment. The average direct medical cost was $\mathrm{GH} \not 11.9$ (US\$3.1) per treatment and the average cost on medicine alone was GHф12.4 (US\$3.3).

Out of the 140 patients who incurred direct medical costs, $74.3 \%$ (104 of 140) were insured and $25.7 \%$ (36 of 140) were not insured into the NHIS. The average direct medical cost by the uninsured was higher (GH\&14.9/ US\$3.9) than the insured (GHळ10.9/US\$2.9).

Out of the total 393 patients, $82.2 \%$ (323 of 393) spent on direct non-medical costs during the fever treatment. About $77.4 \%$ (304 of 393) of respondents incurred transportation cost and the average transportation cost to and from healthcare providers was GH\&10.4 (US\$2.7). The average direct non-medical cost (transportation and other costs such as lodging, meals and telephone expenses) was GH\&11.7 (US\$3.1). The average direct cost representing medical and non-medical cost was GH८14.9/US\$3.9 (range: GH $\not 0.2 / \mathrm{US} \$ 0.1-\mathrm{GH} \not 166 / \mathrm{US} \$ 43.7)$. Average

Table 4 Direct and indirect costs of fever treatment (GHC/US\$)

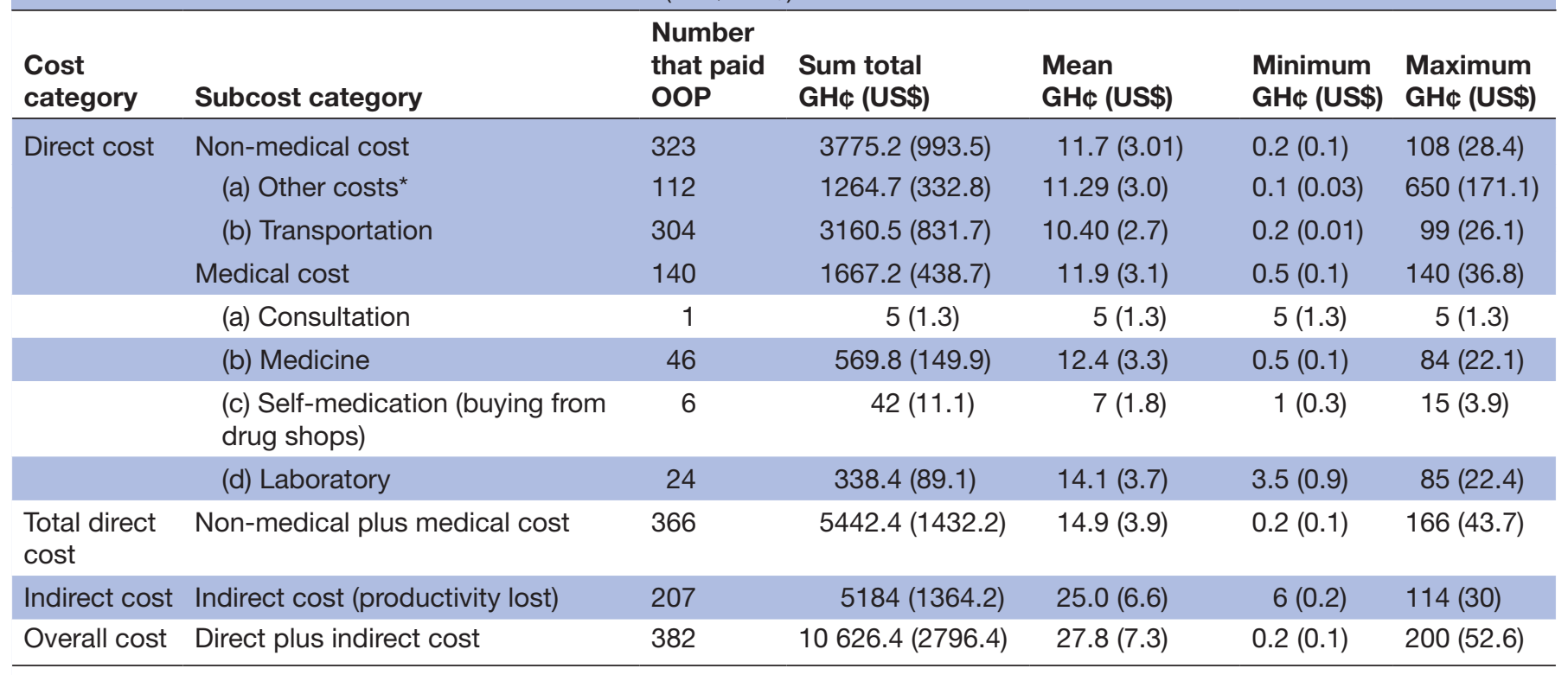

*Lodging, meals and telephone expenses.

OOP, out-of-pocket. 
Table 5 Cost of fever treatment by insurance status

\begin{tabular}{llcrrr}
\hline Insurance status & Number that paid OOP & $\begin{array}{l}\text { Sum } \\
\text { GH\$ (US\$) }\end{array}$ & $\begin{array}{l}\text { Mean } \\
\text { GH\$ (US\$) }\end{array}$ & $\begin{array}{l}\text { Minimum } \\
\text { GH\$ (US\$) }\end{array}$ & $\begin{array}{l}\text { Maximum } \\
\text { GH\$ (US\$) }\end{array}$ \\
\hline Insured & 321 & $7945.3(2090.9)$ & $24.8(6.5)$ & $0.2(0.1)$ & $196.5(51.7)$ \\
Uninsured & 61 & $2681.1(705.6)$ & $50(11.6)$ & $0.5(0.1)$ & $200(52.6)$ \\
Total & 382 & $10626.4(2796.4)$ & $27.82(7.32)$ & $0.2(0.1)$ & $200(52.6)$ \\
\hline
\end{tabular}

OOP, out-of-pocket.

indirect cost which relates to productivity lost or income lost for those engaged in income-generating activities was GH 425 (US\$6.6). When indirect cost was calculated for those who were 18 years and above (irrespective of whether they were engaged in any work), the average cost was GHÆ39.7 (US\$10.4).

As presented in table 5 , the average cost incurred in the treatment of fever by the uninsured was greater ( $\mathrm{GH} \not 50 /$ US\$11.6) than their insured counterparts (GHф24.8/ US\$6.5).

\section{Hospitalisation}

Out of the 393 patients interviewed, 13.2\% (52 of 393) were admitted and incurred cost. The average number of days spent by those admitted was 4 days (range 2-7 days). The average cost incurred by those admitted was GH $\not 18.9 / \mathrm{US} \$ 5$ (range: GH $\$ 0.5 / \mathrm{US} \$ 0.1-\mathrm{GH} \not 150 /$ US\$39.5). Out of the 52 patients with fever hospitalised, $75 \%$ (39 of 52) were insured. Surprisingly, the insured paid more hospitalisation cost (GH $\not 20.4$ /US\$5.4) than the uninsured (GHф14.6/US\$3.8).

\section{Number of days lost to work due to fever}

The average number of days a fever episode prevented patients from working was about 5 days for patients and 4 days for caregivers. Controlling for the patients actively engaged in income-generating activities, the number of days lost still remained at 5 days. The number of school days lost by patients attending school due to fever was 3 days (range: $1-7$ days).

\section{DISCUSSION}

We examined the health-seeking behaviours as well as cost of fever treatment to households in the Kassena-Nankana East and West districts of Ghana. Our findings showed that treatment of fever cases without confirmation tests is prevalent. This is not in line with WHO recommendation that all persons from endemic areas with suspected malaria should be examined for evidence of infections with malaria parasites by RDT or microscopy before treatment. ${ }^{6}$ The Roll Back Malaria (RBM) partnership had set up a target that at least $80 \%$ of patients with malaria are diagnosed and treated with effective antimalarial medicines within 24 hours of the onset of illness. ${ }^{20}$ Prompt diagnosis and timely treatment can ease illness progression to severe stages and consequently decrease mortality. ${ }^{21}$ Given that in our study, less than half of patients $(49.6 \%)$ had diagnostic tests (RDTs or microscopy) to confirm malaria and only $24 \%$ took antimalarial within 24 hours of onset of illness is not encouraging.

Some reasons for the low use of diagnostic test before treatment could be limited supply of RDTs at health facilities $^{22}$ and high care seeking at pharmacy and licensed chemical shops where diagnostic tests are mostly not conducted before treatment. Also, patients may delay seeking care because of financial constraint or they simply want to be sure they are experiencing symptoms of malaria before they seek care. Our findings of $24 \%$ is lower compared with a study in Ethiopia where $52.4 \%$ of participants sought treatment within 24 hours of fever onset. $^{23}$ This suggests that more efforts are still needed to achieve the RBM target in Ghana.

In our study, $57.6 \%$ of patients who did not test for malaria still took an antimalarial. It has been reported in a previous study that practitioners, particularly in the pharmacy or drug shops, use raised body temperature (fever) to determine malaria instead of diagnostic tests. Moreover, some $(30 \%)$ of these practitioners indicated that an RDT negative result does not mean no malaria illness and would therefore prescribe ACT. ${ }^{24}$ Similarly, in a study on private retail pharmacies in Ghana, $60 \%$ of patients who tested negative for malaria were still given AL (ACT).$^{25}$

Since some of the reasons for the treatment failure of chloroquine included non-compliance with duration of treatment regimen and misdiagnosis, ${ }^{26}$ proper diagnosis and rational use of ACTs are crucial in the efforts to reduce fever/malaria burden and to prevent the emergence of ACT resistance and treatment failure in the near future. Given the community preference for pharmacy/ chemical shops for seeking malaria treatment and the high rate of taking antimalarials without RDT testing, the provision of proper RDT training to these shop owners and allowing them to do malaria RDT on patients before selling antimalarials may improve malaria case management in Ghana. Previous studies that piloted the use of RDT in private medicine retail outlets reported positive effects of RDTs in improving malaria case management and curtailing the dispensing of antimalarials to patients without malaria. $^{27-29}$

Despite the fact that AA and AL are the most stocked ACTs in the market, ${ }^{30}$ our study revealed that the most used ACT in the KND was DP (35.1\%), followed by AA $(34.3 \%)$ and $\mathrm{AL}(21.0 \%)$. DP is the most expensive ACT 
sold in both the health facilities and the chemical shops in the districts. For instance, whereas AA cost about GH $45 / \mathrm{US} \$ 1.3$ in the pharmacy/chemical shops, P-Alaxin (DP) cost about GH $\not 10 /$ US\$2.6, twice the price of AA. Contrary to our findings of DP being the most used ACT, a previous qualitative study conducted in the same study area reported that respondents preferred AL to other ACTs because AL was perceived to be more effective and has minimal side effects compared with the other ACTs, especially AA. ${ }^{31}{ }^{32}$ The high reported usage of DP in our study could be that patients and prescribers were interested in trying a new drug. This finding supports the importance of treatment options to take care of patients who react to certain ACTs.

The study revealed that a large proportion of patients with fever were treated with ACTs (69\%) and a little over $50 \%$ obtained the ACTs from formal health facilities (hospitals, health centres, clinics and CHPS). High utilisation of formal health facilities for malaria/fever treatment has been reported in previous studies. ${ }^{233-36}$ The high use of formal health facilities in our study could be attributed to the NHIS as about $83 \%$ of the patients in this study were enrolled into the scheme. Although ACTs are dispensed in formal health facilities, the buying of ACTs at the pharmacy/licensed chemicals shops was quite high $(41.4 \%)$. This is worrisome given that most of the pharmacy/licensed chemical shops do not carry out diagnostic tests before treatment.

The average cost of treating fever in the KND was GH 427.8 /US $\$ 7.3$. The average cost of fever treatment in our study is lower than other cost estimates in other similar studies conducted in other parts of Ghana. ${ }^{24}$ For instance, a study conducted in the middle belt of Ghana reported that households incurred an average cost of US $\$ 14.6$ for the treatment of a fever episode. ${ }^{2}$ However, another study in the Upper West region of northern Ghana reported a lower average cost of US $\$ 4.91$ in treating an under-5 malaria case. ${ }^{4}$ A study in Kenya reported an average cost of US $\$ 3.46^{16}$ and another study in Ethiopia reported a median cost of US $\$ 5.06^{37}$ in treating an uncomplicated malaria case. Comparing the costs of fever treatment with other substantial diseases such as pneumonia, it was reported in Pakistan that the average household cost for the treatment of pneumonia was between US $\$ 1.46$ and US\$7.60. However, in Ecuador, the direct cost associated with hospitalisation of children with severe pneumonia was US\$33. ${ }^{38}$

In our study, transportation cost was considerably high (US\$2.7). Transportation costs hinder access to healthcare at health facilities and have the tendency to decrease or delay treatment. ${ }^{39-41}$ Even though the government has made considerable progress in providing health facilities such as CHPS compounds to rural communities, our findings showed that people still spend substantial amounts on transport. This shows that more efforts are still needed in the provision of health facilities to hardto-reach communities to reduce travel distance and transport costs.
The average treatment cost for fever is relatively high given that the poverty rate in the region is $44.4 \%$ (representing the second poorest region in the country). ${ }^{11}$ This estimated cost of treatment represents 4.5 times the daily minimum wage (US\$1.6) earned by Ghanaians in unskilled paid work. This amount could have catastrophic effect on households, particularly if more than one household member gets fever within the same period. ${ }^{16}$ High treatment costs can prevent the poor from seeking care when they have fever, and impoverish households who seek care when they have an episode of fever. ${ }^{242}$

The NHIS covers the treatment of about $95 \%$ of diseases in Ghana, including malaria. The benefit package covers both inpatient and outpatient care, emergency and transfer services, ${ }^{43}$ and the insured are generally not expected to incur direct medical cost in treating malaria at any formal health facility.

In this study, the uninsured incurred more direct cost (GH $14.9 / \mathrm{US} \$ 3.9)$ than the insured (GH $\not 10.9 / \mathrm{US} \$ 2.9)$, which reflects the positive effect of the NHIS in reducing cost of treatment to patients. Overall, the average cost incurred in the treatment of fever by the uninsured was 1.8 times the cost incurred by the insured. Thus, the uninsured paid about US $\$ 5$ more than the insured, which is consistent with many findings where the uninsured paid more than the insured in treating malaria. ${ }^{33} 3644$

The insured, however, paid more hospitalisation costs (GH $420.4 /$ US\$5.4) than the uninsured (GH\&14.6/ US\$3.8). This finding is contrary to findings of a previous study that reported that hospitalisation cost was lower for the insured inpatients (GH $44 / \mathrm{US} \$ 2.7)$ than the uninsured inpatients (GH $6.4 / \mathrm{US} \$ 4.3)$ even though the difference was not statistically significant $(p=0.2330) .{ }^{18}$ A possible reason for our finding is that the wealthy are usually more insured than the poor, ${ }^{45}$ and in times of critical situations like hospitalisation, they may be willing to pay for expensive medication compared with the uninsured who cannot afford expensive medication.

Direct medical costs (GH\&11.9/US\$3.1) incurred by patients (particularly the insured) could be due to laboratory test carried out at private places and buying of antimalarial and other drugs outside the health facilities in cases of stock-outs. ${ }^{246}$ Health facilities should therefore be adequately resourced to avoid patients paying for medicines and other services outside the health facilities at high costs.

The average indirect cost (GH $425.0 / \mathrm{US} \$ 6.6)$ was 1.7 times the direct cost (GH $14.9 / \mathrm{US} \$ 3.9)$. This is consistent with many findings where the indirect costs of malaria treatment were higher than the direct costs of treatment. $^{23647}$ Therefore, efforts to improve access to healthcare and reduce the financial burden to households in the treatment of fever should not only be limited to direct medical costs but also indirect costs.

\section{Strengths and limitations of the study}

This study has provided insights on the health-seeking behaviours of people with fever and the cost incurred in 
the treatment of fever in the context of a malaria-endemic area in northern Ghana.

Another strength of the study is the inclusion of indirect costs in the cost estimation of fever treatment. This cost component is an important cost element that is often ignored in cost studies which results in underestimation of cost of illness. The study used the framework of the Navrongo HDSS which has a database of all individuals and households in the study districts for the selection of respondents which allowed representativeness of the study.

Recall bias is a possible limitation of the study as respondents were asked to recall expenditure over a 2-week period which could lead to overestimation or underestimation of costs. However, the probing technique used in data collection may minimise the bias. The use of selfreported fever as a proxy for malaria is a potential limitation. Nevertheless, given that fever is mostly associated with malaria, ${ }^{24} 489$ the effect will be minimal.

\section{Conclusions}

Though patients had good access to antimalarial medicine, prompt treatment, that is, treatment within 24 hours of onset of fever as well as diagnostic testing before treatment of suspected malaria is low when compared with the RBM target of $80 \%$. The average fever treatment cost was relatively high when compared with average earnings of households in Ghana.

Enrolment into the NHIS reduced the cost of fever treatment remarkably. It is important to improve access to malaria diagnosis, ACTs and community enrolment into the NHIS in order to improve case management of fever/ malaria and thereby accelerate Ghana's drive towards universal health coverage.

\section{Author affiliations}

${ }^{1}$ Institute of Health Research, University of Health and Allied Sciences, Ho, Volta Region, Ghana

${ }^{2}$ School of Medicine, C K Tedam University of Technology and Applied Sciences, Navrongo, Upper East, Ghana

${ }^{3}$ Social Science Department, Navrongo Health Research Centre, Navrongo, Upper East Region, Ghana

${ }^{4}$ School of Public Health, University of Health and Allied Sciences, Ho, Volta Region, Ghana

${ }^{5}$ School of Public Health, University of Ghana, Legon, Ghana

\section{Twitter Philip Ayizem Dalinjong @Philip Dalinjong}

Acknowledgements We wish to express our gratitude to the Navrongo Health Research Centre for the institutional support to undertake the study. We are grateful to the study respondents, data collectors, data managers and the data entry clerks for the support provided in the conduct of this study.

Contributors MAD, PW, PAD, SC, IA, A0, PBA and PA contributed to the conception, design, data collection, analysis, interpretation and drafting of the manuscript. MI, RKA, DK and AKM contributed to data analysis, interpretation and drafting of the manuscript. All authors read and approved the final manuscript.

Funding This research was funded by the Bill and Melinda Gates Foundation and facilitated by the INDEPTH Network.

Disclaimer The funder has no role in the study design, data collection, analysis, writing and publication of this manuscript.

Competing interests None declared.
Patient consent for publication Not required.

Ethics approval Ethical approval for the study was obtained from the Navrongo Health Research Centre Institutional Review Board (Approval ID: NHRCIRB129). Written informed consent was obtained from all adult participants and caregivers/ parents of children before interviews were conducted. Assent was sought from participants who were between 12 and 17 years.

Provenance and peer review Not commissioned; externally peer reviewed.

Data availability statement All data relevant to the study are included in the article or uploaded as supplemental information. Relevant data based on which conclusions were made are included in the document. The questionnaire is included as supplementary material.

Supplemental material This content has been supplied by the author(s). It has not been vetted by BMJ Publishing Group Limited (BMJ) and may not have been peer-reviewed. Any opinions or recommendations discussed are solely those of the author(s) and are not endorsed by BMJ. BMJ disclaims all liability and responsibility arising from any reliance placed on the content. Where the content includes any translated material, BMJ does not warrant the accuracy and reliability of the translations (including but not limited to local regulations, clinical guidelines, terminology, drug names and drug dosages), and is not responsible for any error and/or omissions arising from translation and adaptation or otherwise.

Open access This is an open access article distributed in accordance with the Creative Commons Attribution Non Commercial (CC BY-NC 4.0) license, which permits others to distribute, remix, adapt, build upon this work non-commercially, and license their derivative works on different terms, provided the original work is properly cited, appropriate credit is given, any changes made indicated, and the use is non-commercial. See: http://creativecommons.org/licenses/by-nc/4.0/.

\section{ORCID iDs}

Maxwell Ayindenaba Dalaba http://orcid.org/0000-0002-7101-769X

Philip Ayizem Dalinjong http://orcid.org/0000-0002-7982-9975

Alfred Kwesi Manyeh http://orcid.org/0000-0002-7005-5707

\section{REFERENCES}

1 WHO. The "World malaria report 2019" at a glance. Available: https:// www.who.int/news-room/feature-stories/detail/world-malaria-report2019 [Accessed 14 Jun 2021].

2 Tawiah T, Asante KP, Dwommoh RA, et al. Economic costs of fever to households in the middle belt of Ghana. Malar J 2016;15:68.

3 Shretta R, Silal SP, Malm K, et al. Estimating the risk of declining funding for malaria in Ghana: the case for continued investment in the malaria response. Malar J 2020;19:196.

4 Dalaba MA, Welaga P, Oduro A, et al. Cost of malaria treatment and health seeking behaviour of children under-five years in the upper West region of Ghana. PLoS One 2018;13:e0195533.

5 Maheu-Giroux M, Castro MC. Cost-effectiveness of larviciding for urban malaria control in Tanzania. Malar J 2014;13:477.

6 WHO. World malaria report, 2014. Available: http://www.who.int/ mediacentre/factsheets/fs094/en/

7 Osei-Safo D, Agbonon A, Konadu DY, et al. Evaluation of the quality of artemisinin-based antimalarial medicines distributed in Ghana and togo. Malar Res Treat 2014;2014:e806416

8 Ghana Health Service. Anti-Malaria drug policy for Ghana, 2009. Available: http://apps.who.int/medicinedocs/documents/s18072en/ s18072en.pdf

9 Ghana Statistical Service. Ghana - Demographic and health survey 2014, 2014. Available: https://microdata.worldbank.org/index.php/ catalog/2373 [Accessed 23 Jun 2021].

10 Dalaba MA, Akweongo P, Aborigo RA, et al. Cost to households in treating maternal complications in northern Ghana: a cross sectional study. BMC Health Serv Res 2015;15:34.

11 Ghana Statistical Service. Ghana living standard survey round 6 (GLSS 6), 2014.

12 Dalaba MA, Stone AE, Krumholz AR, et al. A qualitative analysis of the effect of a community-based primary health care programme on reproductive preferences and contraceptive use among the KassenaNankana of northern Ghana. BMC Health Serv Res 2016;16:80.

13 Dalinjong PA, Welaga P, Azongo DK, et al. A retrospective analysis of the association between tobacco smoking and deaths from respiratory and cardiovascular diseases in the Kassena-Nankana districts of Northern Ghana. Tob Induc Dis 2015;13:12.

14 Herbst K, Juvekar S, Bhattacharjee T, et al. The indepth data repository: an international resource for longitudinal population and 
health data from health and demographic surveillance systems. J Empir Res Hum Res Ethics 2015;10:324-33.

15 Chatio S, Aborigo R, Adongo PB, et al. Adherence and uptake of artemisinin-based combination treatments for uncomplicated malaria: a qualitative study in northern Ghana. PLoS One 2015;10:e0116856.

16 Alonso S, Chaccour CJ, Elobolobo E, et al. The economic burden of malaria on households and the health system in a high transmission district of Mozambique. Malar J 2019;18:360.

17 Statista. Ghana: daily minimum wage 2010-2020 [online]. Available: https://www.statista.com/statistics/1188375/daily-minimum-wagein-ghana/ [Accessed 7 Jun 2021].

18 Dalaba MA, Akweongo P, Aborigo R, et al. Does the National health insurance scheme in Ghana reduce household cost of treating malaria in the Kassena-Nankana districts? Glob Health Action 2014;7:23848

19 United States dollar (USD) and Ghanaian cedi (GHS) year 2015 exchange rate history. free currency rates (FCR). Available: https:// freecurrencyrates.com/en/exchange-rate-history/USD-GHS/2015 [Accessed 23 Jun 2021].

20 Global Partnership to Roll Back Malaria. A decade of partnerships and results. Geneva: World Health Organization, 2011.

21 Dinko B, Amakpa E, Kweku M, et al. Plasmodium falciparum malaria cases detected for prompt treatment by rapid diagnostic tests in the Ho Teaching Hospital of the Volta Region of Ghana. Parasite Epidemiol Control 2018;3:e00072.

22 Boadu NY, Amuasi J, Ansong D, et al. Challenges with implementing malaria rapid diagnostic tests at primary care facilities in a Ghanaian district: a qualitative study. Malar J 2016;15.

23 Workineh B, Mekonnen FA. Early treatment-seeking behaviour for malaria in febrile patients in Northwest Ethiopia. Malar J 2018;17:406.

24 Danquah DA, Buabeng KO, Asante KP, et al. Malaria case detection using rapid diagnostic test at the community level in Ghana: consumer perception and practitioners' experiences. Malar $J$ 2016; $15: 34$

25 Audu R, Anto BP, Koffuor GA, et al. Malaria rapid diagnostic test evaluation at private retail pharmacies in Kumasi, Ghana. $J$ Res Pharm Pract 2016;5:175-80.

26 Amponsah $\mathrm{AO}$, Vosper $\mathrm{H}$, Marfo AFA. Patient related factors affecting adherence to antimalarial medication in an urban estate in Ghana. Malar Res Treat 2015;2015:e452539

27 Visser T, Bruxvoort K, Maloney K, et al. Introducing malaria rapid diagnostic tests in private medicine retail outlets: a systematic literature review. PLoS One 2017;12:e0173093.

28 Ansah EK, Narh-Bana S, Affran-Bonful H, et al. The impact of providing rapid diagnostic malaria tests on fever management in the private retail sector in Ghana: a cluster randomized trial. BMJ 2015;350:h1019.

29 Audu R, Anto BP, Koffuor GA, et al. Malaria rapid diagnostic test evaluation at private retail pharmacies in Kumasi, Ghana. $J$ Res Pharm Pract 2016;5:175.

30 Tivura M, Asante I, van Wyk A, et al. Quality of artemisinin-based combination therapy for malaria found in Ghanaian markets and public health implications of their use. BMC Pharmacol Toxicol 2016:17:48.

31 Chatio S, Aborigo R, Adongo PB, et al. Adherence and uptake of artemisinin-based combination treatments for uncomplicated malaria: a qualitative study in northern Ghana. PLoS One 2015;10:e0116856.

32 Chatio S, Aborigo R, Adongo PB, et al. Factors influencing adverse events reporting within the health care system: the case of artemisinin-based combination treatments in northern Ghana. Malar J 2016;15:125

33 Ayindenaba Dalaba M, Akweongo P, Aborigo R, et al. Does the National health insurance scheme in Ghana reduce household cost of treating malaria in the Kassena-Nankana districts? Glob Health Action 2014;7:23848.

34 Ameh S, Welaga P, Kabiru CW, et al. Factors associated with appropriate home management of uncomplicated malaria in children in Kassena-Nankana district of Ghana and implications for community case management of childhood illness: a cross-sectional study. BMC Public Health 2015;15:458.

35 Abokyi LN, Asante KP, Mahama E, et al. Use of antimalarial in the management of fever during a community survey in the Kintampo districts of Ghana. PLoS One 2015;10:e0142106.

36 Dalaba MA, Welaga P, Oduro A, et al. Cost of malaria treatment and health seeking behaviour of children under-five years in the upper West region of Ghana. PLoS One 2018;13:e0195533.

37 Hailu A, Lindtjørn B, Deressa W, et al. Economic burden of malaria and predictors of cost variability to rural households in south-central Ethiopia. PLoS One 2017;12:e0185315.

38 Sabin LL, Estrella B, Sempértegui F, et al. Household costs associated with hospitalization of children with severe pneumonia in Quito, Ecuador. Am J Trop Med Hyg 2020;102:731-9.

39 Fenny AP, Asante FA, Enemark U, et al. Malaria care seeking behavior of individuals in Ghana under the NHIS: are we back to the use of informal care? BMC Public Health 2015;15:370.

40 Lwenge M. Health seeking behaviours for malaria treatment: a study among international students in the University of Ghana Legon. thesis, University of Ghana, 2018. Available: http://ugspace.ug.edu. $\mathrm{gh} /$ handle/123456789/26145

41 Amegbor PM. An assessment of Care-Seeking behavior in AsikumaOdoben-Brakwa district: a triple Pluralistic health sector approach. Sage Open 2017;7:215824401771068.

42 Ezenduka CC, Falleiros DR, Godman BB. Evaluating the treatment costs for uncomplicated malaria at a public healthcare facility in Nigeria and the implications. Pharmacoecon Open 2017;1:10.1007/ s41669-017-0021-8:185-94.

43 Fenny AP, Hansen KS, Enemark U, et al. Quality of uncomplicated malaria case management in Ghana among insured and uninsured patients. Int J Equity Health 2014;13:63.

44 Okoroh J, Essoun S, Seddoh A, et al. Evaluating the impact of the National health insurance scheme of Ghana on out of pocket expenditures: a systematic review. BMC Health Serv Res 2018;18:426.

45 van der Wielen N, Falkingham J, Channon AA. Determinants of national health insurance enrolment in Ghana across the life course: are the results consistent between surveys? Int J Equity Health 2018;17:10.1186/s12939-018-0760-x.

46 Dalinjong PA, Wang AY, Homer CSE. Has the free maternal health policy eliminated out of pocket payments for maternal health services? views of women, health providers and insurance managers in northern Ghana. PLoS One 2018;13:e0184830.

47 Zakaria $\mathrm{HB}$, Asante FA. Economic cost of malaria treatment under the health insurance scheme in the Savelugu-Nanton district of Ghana. Ghana J Dev Stud 2015;10:1.

48 Prevention C-C for DC and. CDC - Malaria - diagnosis \& treatment (United States) - treatment (U.S.) - Guidelines for clinicians (Part 1), 2020. Available: https://www.cdc.gov/malaria/diagnosis treatment/ clinicians1.html [Accessed 14 Jun 2021].

49 Ghana Statistical Service. Ghana demographic health survey, 2014, 2014. 